\title{
Ocena rozwoju degradacji zmęczeniowej stali P91 na podstawie zmian kąta fazowego sygnału prądowirowego
}

\author{
Evaluation of fatigue degradation in the P91 steel \\ based on changes eddy current phase angle signal
}

\section{Streszczenie}

Badania dotyczyły oceny możliwości monitorowania rozwoju degradacji stali P91 pod wpływem zmiennych obciążeń cyklicznych, na podstawie zmian wartości kąta fazowego sygnału prądowirowego mierzonej w kolejnych cyklach zmęczeniowych. Na podstawie badań zależności wartości kąta fazowego sygnału prądowirowego od stanu naprężeń (rozciągających i ściskających) w próbce poddanej obciążeniem zmęczeniowym stwierdzono niemal liniowy wpływ wielkości i kierunku naprężenia na ten parametr. Badania w zakresie oceny stopnia uszkodzenia zmęczeniowego próbek realizowano podczas zatrzymania prób zmęczeniowych po określonej liczbie cykli, przy zerowej sile obciążenia, w kilku miejscach, wzdłuż osi głównej próbki. Na tej podstawie możliwa była lokalizacja miejsc rozwoju uszkodzeń zmęczeniowych przed powstaniem pęknięcia.

\section{Materiał i metodyka badania}

Badania wykonano na próbkach płaskich, pobranych z fragmentu rury z żarowytrzymałej stali P91 przeznaczonej do pracy w podwyższonej temperaturze. Parametry wyznaczone w statycznej próbie rozciągania (tabl. I) pozwoliły dobrać zakres amplitudy naprężenia w testach zmęczeniowych od 360 do $380 \mathrm{MPa}$.

Dla oceny zależności wartości kąta fazowego od wielkości i charakteru naprężenia przeprowadzono pomiary tego parametru podczas próby statycznego

Dr inż. Dominik Kukla, mgr inż. Paweł Grzywna - Instytut Podstawowych Problemów Techniki PAN, dr inż. Andrzej Zagórski - Politechnika Warszawska.
Abstract

The investigations concerned the possibility of monitoring the degradation of P91 steel during cyclic loading, based on the changes in phase angle of eddy current signal measured at successive fatigue cycles. The investigations of the influence of the stress state (compressive and tensile) in the sample on the values of phase angle evidence almost linear dependence of this parameter and the value and direction of the stress. The estimation of the fatigue failure degree of the samples was realized after specified number of cycles. The measurements were performed in several points along the principal axis of the sample. Based on this investigations, it was possible to detect the zones in which the fatigue failure were evolved, before fracture occurred. ściskania i rozciągania w zakresie naprężenia od -400 do +400 MPa, co dla uzyskanych wartości parametru Re można uznać za zakres sprężysty. Podczas testu wykonano pomiar kąta w centralnej części próbki przy naprężeniu rozciągającym o wartości: 0, 100, 200, 300 oraz $400 \mathrm{MPa}$, a następnie przy naprężeniu ściskającym o wartości: $-100,-200,-300$ i $-400 \mathrm{MPa}$.

Badania wytrzymałościowe i zmęczeniowe wykonano na maszynie hydraulicznej MTS 810, przy częstotliwości $20 \mathrm{~Hz}$, na próbkach płaskich, o geometrii umożliwiającej wykonanie pomiarów z użyciem prądowirowej sondy ołówkowej. Badania tego typu stali prowadzono także dla innych geometrii próbki, a wyniki zawarto $\mathrm{m}$. in. w $[1,2]$. Szkic próbki ze wskazaniem miejsc pomiarów kąta fazowego pokazano na rysunku 1.

Badania stopnia uszkodzenia próbek pod wpływem zmiennych obciążeń cyklicznych dokonano przy użyciu apartu MIZ 27 SI firmy ZETEC przy zastosowaniu 
Tablica I. Parametry wytrzymałościowe badanej stali P91 oraz według PN-EN 10216-2:2004

Table I. Mechanical properties of tested P91 steel and acc. to PN-EN 10216-2:2004

\begin{tabular}{|c|c|c|c|}
\hline Parametry & Rm, MPa & Re, MPa & A, \% \\
\hline P91 materiał badany & 662 & 497 & 25 \\
\hline Wg PN: 10216-2:2004 & $630 \div 830$ & $>450$ & $17 \div 19$ \\
\hline
\end{tabular}

Rys. 1. Szkic próbki ze wskazaniem miejsc pomiaru kąta fazowego Fig. 1. Scheme of specimen with marked location of phase angle measurements

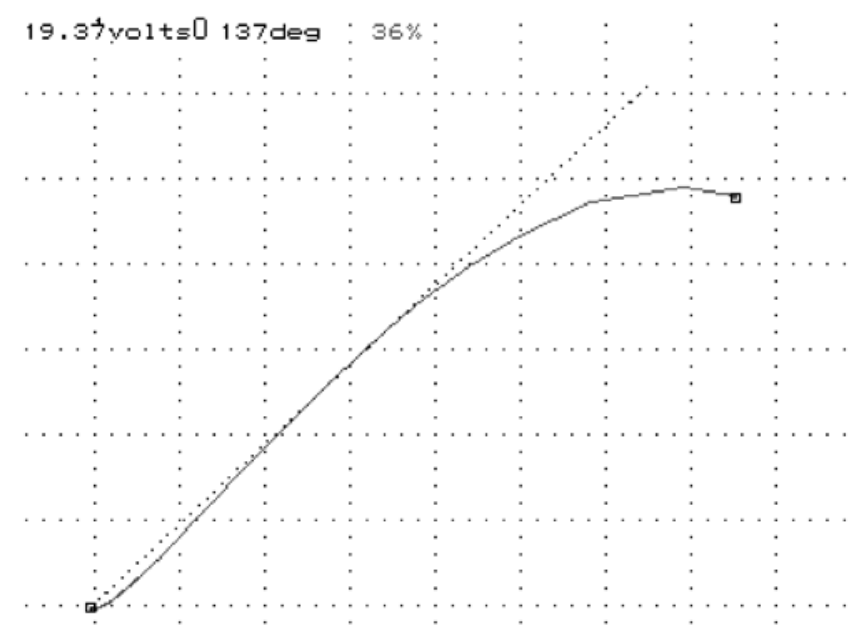

Rys. 2. Metodyka pomiaru kąta fazowego z zastosowaniem liniowej aproksymacji stycznej do krzywej oddalenia

Fig. 2. Method of phase angle measurement with the use of linear approximation of the tangent to the curve distance

sondy o zakresie częstotliwości od $500 \mathrm{kHz}$ do $1 \mathrm{MHz}$. Procedura pomiaru kąta fazowego realizowana była z wykorzystaniem oprogramowania dostępnego w aparacie MIZ $27 \mathrm{SI}$ (rys. 2) i sprowadzała się do pomiaru kąta nachylenia linii stycznej do krzywej oddalenia (lift off) dla materiału próbki w miejscach wyznaczonych do pomiaru, zgodnie ze schematem na rysunku 1 . Spośród innych metod pomiaru zmian parametrów prądowirowych testowanych przez autorów [3] ta wydaje się najbardziej powtarzalna i precyzyjna. Pomiary realizowano na próbkach zamontowanych w szczękach maszyny wytrzymałościowej, przy zerowej sile obciążenia, najpierw przed testem zmęczeniowym (w celu uzyskania sygnału referencyjnego), a następnie podczas kolejnych zatrzymań testu po określonej liczbie cykli, dobranej w zależności od amplitudy naprężenia.

Wybór lokalizacji punktów pomiaru kąta i ich liczba wynikały $z$ tendencji do pękania próbek zarówno w środku części pomiarowej, jak i w obszarze redukcji przekroju, zarówno w dolnej, jak i górnej części. Ponadto $z$ uwagi na powierzchniowy charakter pomiaru metodą prądów wirowych wykonano je po obu stronach próbki. Taka procedura pomiarów pozwala na identyfikację i lokalizację uszkodzenia zmęczeniowego we wczesnym etapie jego rozwoju, poprzedzającym dynamiczny wzrost odkształcenia, a także umożliwia monitorowanie jego rozwoju na podstawie dynamiki zmian wartości kąta fazowego.

\section{Wyniki badań}

Na podstawie pomiarów kąta fazowego próbki ze stali P91 pod obciążeniem rozciągającym i ściskającym o wartości od -400 do $400 \mathrm{MPa}$ stwierdzono niemal liniową zależność tego parametru od wielkości i kierunku naprężenia, co obrazuje wykres na rysunku 3.

$\mathrm{Na}$ wykresie tym przedstawiono uśrednione wyniki pomiarów z obu stron próbki, zarówno kąta linii stycznej do krzywej oddalenia, jak i linii siecznej, łączącej dwa skrajne punktu krzywej od efektu lift off. Niezależnie od zastosowanej metodyki pomiaru wartość zmierzonego kata zmienia się proporcjonalnie do wartości obciążenia próbki. Wartości zmierzonych kątów fazowych nie różnią się znacząco dla szerokiego zakresu obciążenia, tym niemniej uwidoczniono zależność tego parametru od kierunku i wartości naprężenia.

Kolejne trzy wykresy przedstawiają zmiany wartości kąta fazowego sygnału prądowirowego $w$ funkcji liczby cykli zmęczeniowych dla trzech próbek poddanych testom zmęczeniowym o amplitudzie naprężenia wartości 360 (rys. 4), 370 (rys. 5) i $380 \mathrm{MPa}$ (rys. 6). Poszczególne linie na wykresie przedstawiają zmianę mierzonego parametru $w$ różnych miejscach próbki w funkcji liczby cykli, przy czym linia zielona prezentuje wynik uśredniony dla obu części chwytowych próbki i stanowi poziom odniesienia dla zmian w pozostałych punktach. Na podstawie spadku wartości kąta fazowego wraz z rozwojem degradacji zmęczeniowej można wskazać miejsca, gdzie rozwija się ona najszybciej i gdzie można spodziewać się inicjacji pęknięcia. Różnice pomiędzy wartością referencyjną kąta fazowego (część chwytowa) a wartościami w pewnych obszarach

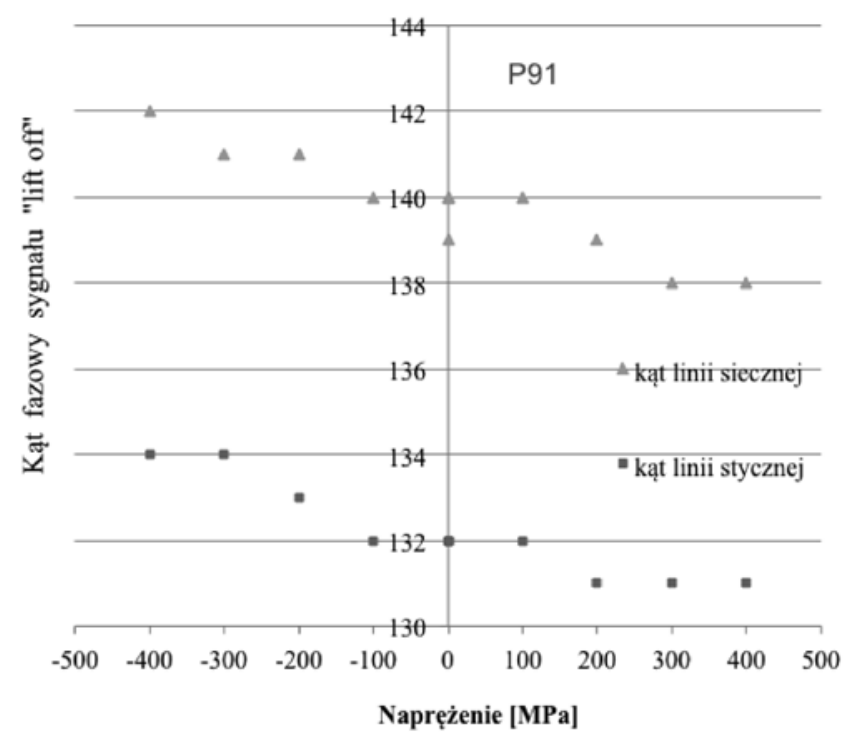

Rys. 3. Zależność kąta fazowego od wartości naprężenia

Fig. 3. Function of phase angle and intensity of stress 
części pomiarowej rosną wraz ze wzrostem amplitudy naprężenia. Różnice te osiągają maksymalne wartości w ostatnim etapie procesu zmęczenia, ale jeszcze przed pęknięciem próbki i wynoszą odpowiednio: $3^{\circ}$ dla amplitudy $360 \mathrm{MPa}, 5^{\circ}$ dla $370 \mathrm{MPa}$ i $5,5^{\circ}$ dla amplitudy $380 \mathrm{MPa}$. Zmiany te można uzasadnić, m.in. lokalnym wzrostem poziomu naprężeń resztkowych powstałych w wyniku obciążeń cyklicznych, inicjacją mikropęknięć generowanych lokalnym uplastycznieniem (np. wokół twardych wtrąceń) lub też lokalną zmianą składu spowodowaną procesami wydzieleniowymi. Wielkość tych zmian (w porównaniu z wielkością zmian wartości kątów uzyskanych dla próbki pod statycznym obciążeniem $400 \mathrm{MPa}$ ) oraz dynamika ich rozwoju w kolejnych cyklach zmęczenia sugeruje ich związek z procesami degradacji mikrostruktury w tym procesie. Na wartość kąta fazowego sygnału prądowirowgo mogą wpływać (poza stanem naprężeń) lokalne zmiany składu chemicznego (np. procesy wydzieleniowe, migracja pierwiastków) czy gęstości (wzrost liczby porów). Ponadto na pewnym etapie rozwoju uszkodzenia zmęczeniowego pojawiają się mikropęknięcia mogące wpływać na zaburzenie linii sił wzbudzanego pola elektrycznego, a tym samym na zmianę wartości kąta fazowego. Tego typu procesy i zjawiska mogą zachodzić

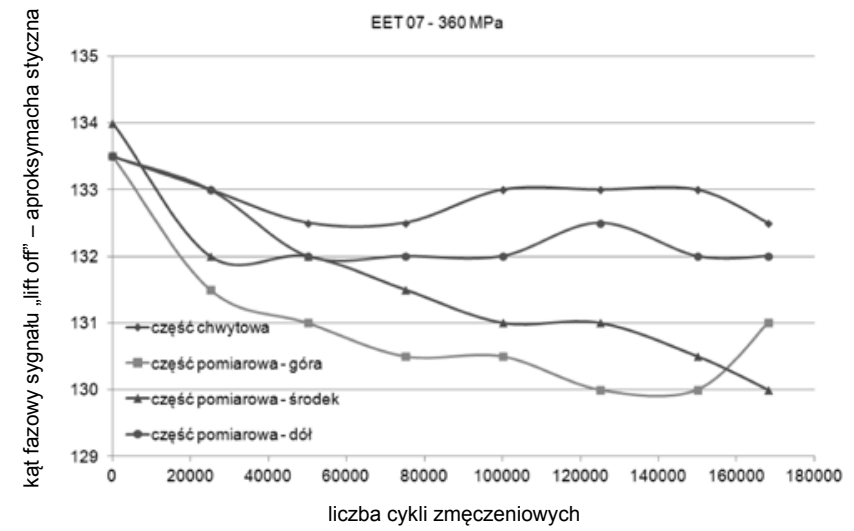

Rys. 4. Zmiany kąta fazowego w kolejnych cyklach zmęczeniowych o amplitudzie naprężenia $360 \mathrm{MPa}$ w różnych miejscach próbki

Fig. 4. Phase angle changes in following load fatigue cycles with $360 \mathrm{MPa}$ stress amplitude in various location in sample

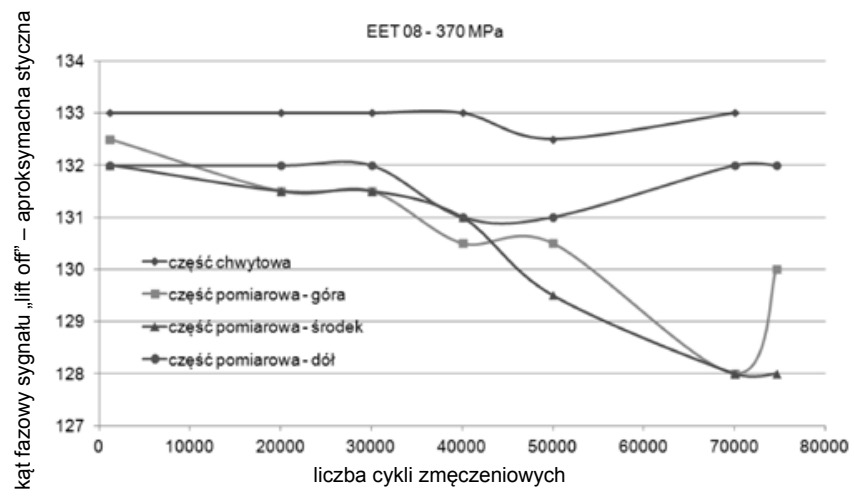

Rys. 5. Zmiany kąta fazowego w kolejnych cyklach zmęczeniowych o amplitudzie naprężenia $370 \mathrm{MPa}$ w różnych miejscach próbki

Fig. 5. Phase angle changes in following load fatigue cycles with $370 \mathrm{MPa}$ stress amplitude in various location in sample w materiale poddanym obciążeniom cyklicznym, a tym samym ich identyfikacja i lokalizacja możliwa jest przy wykorzystaniu metody prądów wirowych.

$\mathrm{Na}$ wszystkich trzech wykresach pokazanych na rysunkach $4 \div 6$ widać stały poziom wartości kąta fazowego dla części chwytowej próbki, we wszystkich pomiarach w kolejnych cyklach obciążenia. Niemal wszystkie pozostałe linie wskazują na mniejszy lub większy spadek wartości kąta wraz ze wzrostem liczby cykli. Dla niektórych punktów pomiarowych można zaobserwować zatrzymanie spadku (rys. 5. - środek próbki), a w większości przypadków wzrost wartości kąta fazowego dla największej liczby cykli zmęczeniowych (rys. 4 i 6). Ostatni pomiar wartości kątów we wszystkich punktach dla danej próbki wykonywany był po teście zakończonym uszkodzeniem próbki. Zatem zatrzymanie tendencji spadkowej wartości kąta w miejscach o największym stopniu uszkodzenia w ostatnim cyklu pomiarowym może wynikać z relaksacji skumulowanych naprężeń resztkowych w obszarach zdegradowanych.

Relaksacja naprężeń w wyniku uszkodzenia próbek miała też różne przyczyny. Charakter zniszczenia próbek w efekcie zmęczenia był różny - inny dla próbki o amplitudzie zmęczenia $360 \mathrm{MPa}$, gdzie doszło

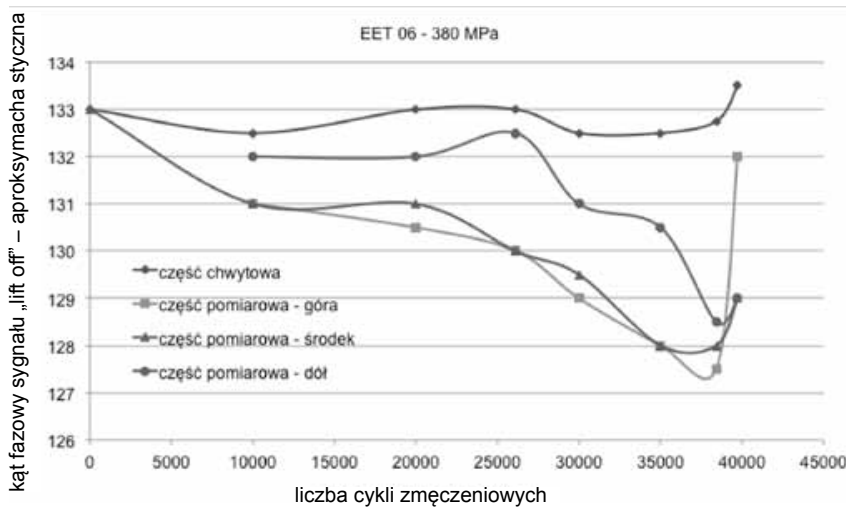

Rys. 6. Zmiany kąta fazowego w kolejnych cyklach zmęczeniowych o amplitudzie naprężenia $380 \mathrm{MPa}$ w różnych miejscach próbki Fig. 6. Phase angle changes in following load fatigue cycles with $380 \mathrm{MPa}$ stress amplitude in various location in sample
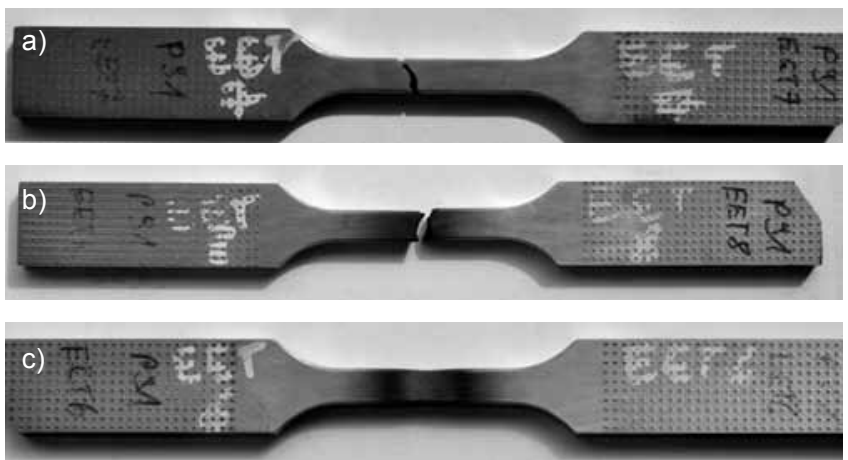

Rys. 7. Złomy próbek po testach zmęczeniowych przy amplitudzie: a) $360 \mathrm{MPa}$, b) $370 \mathrm{MPa}$, c) $380 \mathrm{MPa}$

Fig. 7. Pictures of the samples after the test scrap fatigue with amplitude of: a) $360 \mathrm{MPa}$, b) $370 \mathrm{MPa}$, c) $380 \mathrm{MPa}$ 
do kruchego pęknięcia w górnej połowie próbki (rys. 7a), a inny w przypadku pozostałych próbek, które w ostatnim etapie zmęczenia wykazały efekt przegrzania (rys. 7b, 7c). Stąd też różny charakter zniszczenia w końcowym etapie zmęczenia poszczególnych próbek. Niemniej jednak efekt wzrostu wartości kąta fazowego w ostatnim pomiarze, który wykonywany był (zgodnie z procedurą) w bezpośredniej bliskości powstałego uszkodzenia, można tłumaczyć relaksacją naprężeń zarówno w wyniku pęknięcia, jak i przegrzania próbki w obszarze intensyfikacji procesu degradacji.

\section{Wnioski}

Proces degradacji zmęczeniowej w próbkach ze stali P91 związany jest z koncentracją naprężeń w najmniejszym przekroju próbki, co prowadzi do zlokalizowanego rozwoju odkształceń plastycznych w tym obszarze, inicjacji i rozwoju mikropęknięć oraz utworzenia pęknięcia dominującego i dekohezji próbki. W początkowej fazie procesowi temu towarzyszyć mogą inne zjawiska związane z lokalną zmianą składu, czy gęstości, które wspólnie prowadzą do uszkodzenia zmęczeniowego. Te zjawiska i procesy związane są z minimalnymi, ale lokalnie zintensyfikowanymi zmianami właściwości elektrycznych i magnetycznych, dzięki czemu ich identyfikacja jest możliwa z wykorzystaniem pomiaru kąta fazowego sygnału prądowirowego. Pozwala to na stosunkowo wczesną lokalizację miejsc potencjalnych uszkodzeń i monitorowanie ich rozwoju. Wymaga to jednak opracowania procedur pomiarowo-badawczych z systemem wzorcowania i kalibracji, które pozwolą na identyfikację i analizę minimalnych zmian sygnału prądowirowego wywołanych obciążeniami zmęczeniowymi.

\title{
Literatura
}

[1] Kukla D., Dietrich L., Ciesielski M.: Ocena stopnia uszkodzenia eksploatacyjnego materiału rurociągu parowego na podstawie analizy zmian właściwości zmęczeniowych i mikrostruktury, Acta Mechanica et Automatica, Vol. 5 No. 3 (2011), s. 55-60.

[2] Kukla D., Grzywna P.: Ocena rozwoju procesów zmęczeniowych związanych z lokalnymi odkształceniami na przykładzie stali P91 dla energetyki, Energetyka 8/2012, s. 405-410.
[3] 40 Krajowa Konferencja Badań Nieniszczących, Warszawa, październik 2011, Kukla D., Ciesielski M., Jaśkiewicz A.: Ocena stopnia uszkodzenia zmęczeniowego stali dla energetyki z zastosowaniem metody prądów wirowych - Zeszyty Problemowe Badania Nieniszczące, s. 22.

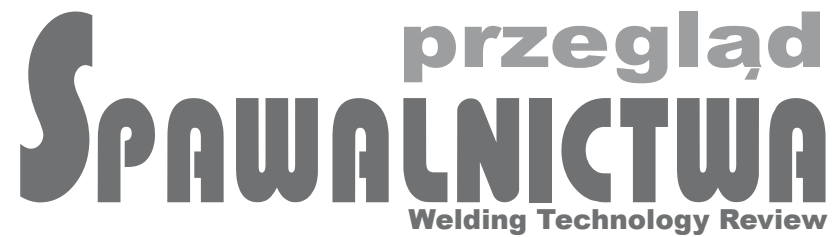

\author{
Redakcja Przegląd Spawalnictwa, ul. Świętokrzyska 14a, 00-050 Warszawa \\ tel.: 2282725 42, fax: 2233614 79; e-mail: pspaw@ps.pl, www.pspaw.ps.pl
}

